\title{
EFFECTS OF METHODS OF ADMITTING EMERGENCIES ON USE OF HOSPITAL BEDS
}

\author{
DAVID MORRIS AND ALAN J. HANDYSIDE \\ Department of Preventive Medicine and Public Health, University of Sheffield
}

\begin{abstract}
Hospitals providing care for the acutely ill encounter the recurrent problem of having to find inpatient accommodation for patients who require immediate admission. The existence of large waiting lists, particularly in surgical specialties, places a further demand on hospital beds. The admission of excessive numbers of waiting-list patients in preference to emergencies may lead to the type of delay in emergency admission, especially for the elderly and those suffering from the effects of chronic, degenerative diseases, which has been described by Gibson, Hughes, and Broughton (1958) and Warren, Cooper, and Warren (1967). In antithesis, the reservation of too many beds for emergencies will entail poor utilization of beds if the anticipated emergencies fail to materialize. In striking a balance between the beds used for patients undergoing elective investigation or treatment, and those reserved for possible emergency admissions, a further complicating factor which must be considered is the wide fluctuation which may occur in the numbers of beds occupied from day to day by patients originally admitted as emergencies.
\end{abstract}

In several studies, attempts have been made statistically to assess or predict the numbers of beds which will be occupied by emergencies, using the observation that the daily demand for such beds may be represented by the Poisson distribution. Newell (1954) presented a series of tables, indicating the numbers of beds required to provide for probable emergency demand at various measurable levels of mean daily demand, and showing also the consequent effects upon levels of bed utilization. Balintfy (1960) evolved a stochastic process, based on theoretical assumptions, to predict the numbers of admissions and discharges. The precision of the model was perhaps reduced by the breadth of the assumptions, and its widespread practical application is currently restricted by the necessity for on-line computer facilities. In a hospital unit concerned only with emergency admissions, which were subject to an imposed short duration of stay, Pike, Proctor, and Wyllie (1963) were able to demonstrate that the numbers of beds occupied from day to day also followed the Poisson distribution. As will be shown, however, the findings of this study cannot be extrapolated to units participating in rotational admission systems for emergencies. By incorporating in his calculations data relating to the duration of stay, Young (1965) suggested a method of control of waiting list admissions which would facilitate emergency admissions while avoiding overcrowding. This method would necessitate the admission of waiting-list patients at very short notice, a procedure which may, in itself, reduce the levels of bed utilization (Morris, Hall, and Handyside, 1969).

In all of these studies, it was assumed that emergencies would be admitted every day to the hospital units under consideration. This assumption is probably tenable only in isolated hospital units, serving discrete catchment populations and obliged to provide accommodation for all the emergencies arising in those populations. In areas of high population density, it is customary to find several hospital units of the same clinical specialty working in relatively close geographical proximity, particularly in the numerically large specialties such as general medicine, general surgery, and orthopaedic surgery. To conserve resources of personnel and equipment, or because of subjective impressions of administrative convenience, the admission of emergencies may be undertaken in rotation by different units within a large hospital, or by different hospitals within an urban area. Thus, an individual unit may admit emergencies on every alternate day, or every third day, or two days of each week, and so on, depending on the number and size of the units involved.

In any unit, the numbers of beds occupied by emergencies will fluctuate from day to day, according to the numbers and duration of stay of the patients admitted. Rotational emergency admission schedules will affect these fluctuations in emergency bed occupancy; for example, the fluctuation will be less where an individual unit admits two cases, on average, every day, than where six emergencies, on average, are admitted every third day. Perhaps the most convenient method of investigating bed utilization, theoretically and practically, is by means 
of computer simulation; it is also possible statistically to estimate certain parameters relating to the use of beds by emergencies. The purpose of this paper is to illustrate the results obtained from simulation, comparing the effects of various rotational admission schedules, where standard data relating to admission rates and duration of stay are used; and to present methods for the statistical estimation of certain parameters of emergency bed use, using data derived from the mean daily admission rate, the distribution of duration of stay, and the characteristics of the admission schedules.

\section{Simulation}

The technique used for this study has been described in detail elsewhere (Handyside and Morris, 1967) and is a Monte Carlo method, involving random sampling from a Poisson distribution for arrival of emergencies, and from a hypothetical distribution of duration of stay. Hospital units of 50 beds were postulated, each unit admitting emergencies at the rate of 1,000 per year. This rate of emergency admission! reflects a throughput of 20 emergencies per bed per year, a rate of turnover currently equalled or exceeded in many of the busier general surgery units in British hospitals.

The distribution of duration of stay used was that illustrated in Fig. 1. Although it is described as a 'hypothetical' distribution, it is basically the distribution of duration of stay of patients admitted as emergencies to general surgery units in the hospitals of the Sheffield Regional Hospital Board, as indi- cated by data obtained from the Hospital In-Patien? Enquiry. However, for the sake of convenience irz data preparation and processing, the upper limit oळ duration of stay was arbitrarily set at 60 days; it is: acknowledged that a small proportion of the emers gencies admitted to 'acute' units in British hospitals stay for periods longer than this.

In assessing the comparative effects of the various rotational admission schedules, a consideration mus $\$$ be the relative difficulty which might be encounteres in planning the optimal use, for the benefit of waiting-list patients, of beds not occupied by emergencies. It is possible to exert a greater measure of control over the use of beds by waiting-list patient? than over those required for emergencies, so that aw almost infinite variety of admission rates and sche dules might be devised for waiting-list patients? Because of this, no attempt was made to super= impose simulated bed occupancy sequences for waiting-list patients on the presented sequences of emergency bed occupancy. Such parallel simula tion would be appropriate and desirable wher\& physical model simulation is used to solve a specifie problem in a particular hospital. In this study? however, it would probably serve only to obscerre the point under consideration, namely, the wayoin which rotational admission schedules may affect emergency bed occupancy.

If it may be assumed that planning of the use of beds for waiting-list patients is facilitated wher variations in the numbers of beds available for these patients are minimized, the degree of difficulty en

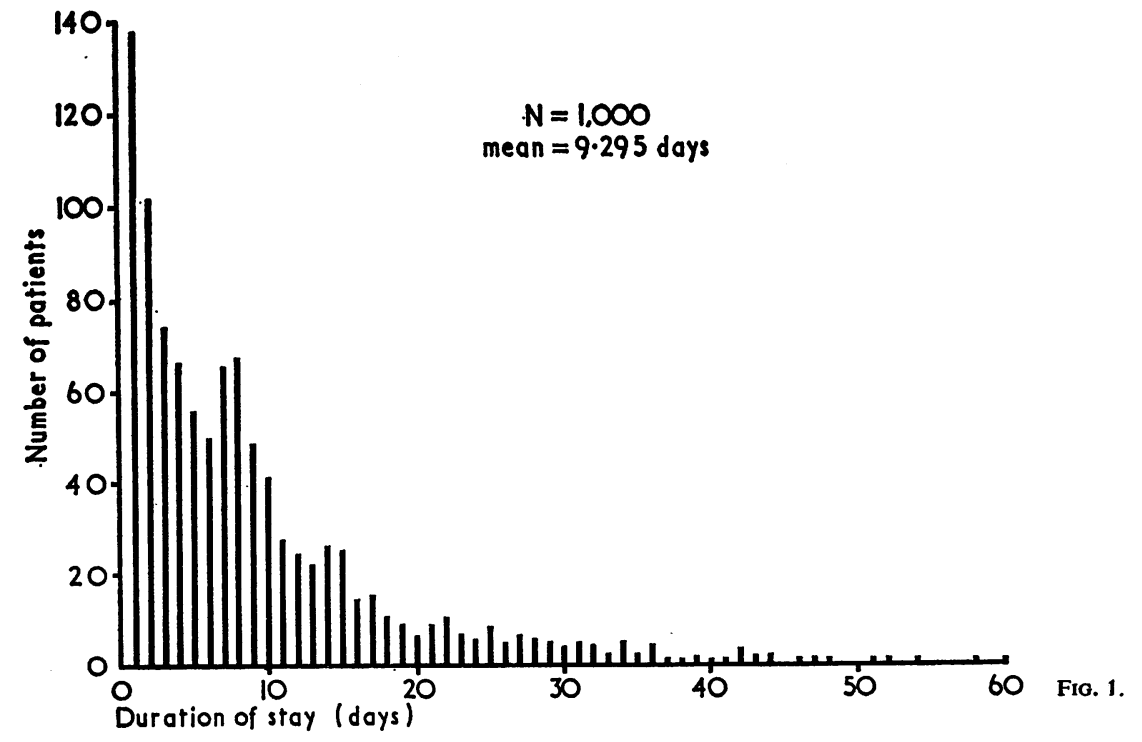


countered in such planning may be inferred from the frequency and extent of the fluctuations in emergency bed occupancy. It is also assumed that it would be undesirable for any of the units postulated in this study to exceed its complement of 50 beds, either by temporary establishment of additional beds or by 'overflow' into other units.

\section{Results}

The simulated bed occupancy sequence presented in Figs. 2 to 10 are representative of analogous time-periods, allowing sufficient time for stabilization after the beginning of simulation, for each of the admission schedules considered. In these sequences, two types of fluctuation may be identified. Small fluctuations occur from day to day, characteristic of the intervals between days of admission, and thus generally related to the number of units whose schedules are associated in an admission system. In some instances, wider fluctuations are spread over periods of weeks, determined by the cyclical nature of the schedules.

The simulated sequence for a unit admitting emergencies every day is shown in Fig. 2. It will be seen that the fluctuations in bed occupancy range from 14 to 39 beds. At any time, this unit might be expected to have at least 10 beds available for use by waiting-list patients. Although the range of fluctuation is wide, increases and decreases are of gradual development, the steepest increment in this sequence being of 15 beds and occurring over a period of one week, from day 47 to day 54 . Despite the unpredictable nature of the fluctuations in emergency bed occupancy, this admission schedule exhibits lesser fluctuations than the other schedules considered and probably affords the greatest facility in planning the use of beds for waiting-list patients.

Figures 3 and 4 show two of the sequences resulting from admission schedules which might be adopted where two units are working in conjunction. In Fig. 3 , emergencies are admitted on every alternate day; in Fig. 4, the schedule is formalized so that each of the two units involved would admit emergencies on the same days every week (in this instance, Monday, Wednesday, and Friday) and cover Sundays alternately. The two sequences are very similar, the main difference being the additional increases in bed occupancy in Fig. 4 when emergencies are admitted consecutively on Sunday and Monday, most obvious at days 57,71 , and 113 . The overall range of fluctuation is comparable with that in Fig. 2, but the dayto-day fluctuations are increased. Thus, although 10 or 12 beds would be constantly available for use by waiting-list patients, it would be less easy to minimize the numbers of beds remaining empty, because of the danger of overflow when there is a sudden increase in emergency bed occupancy.

Two of the admission schedules applicable to combinations of three units are shown in Figs 5 and 6. Figure 5 illustrates the effects of the schedule where each of the three units admits emergencies every third day in strict rotation; and Fig. 6 represents the formalized situation where each of the three units has its own two regular week-days, and covers every third Sunday. The situation is similar to that in Figs 3 and 4, except that the average

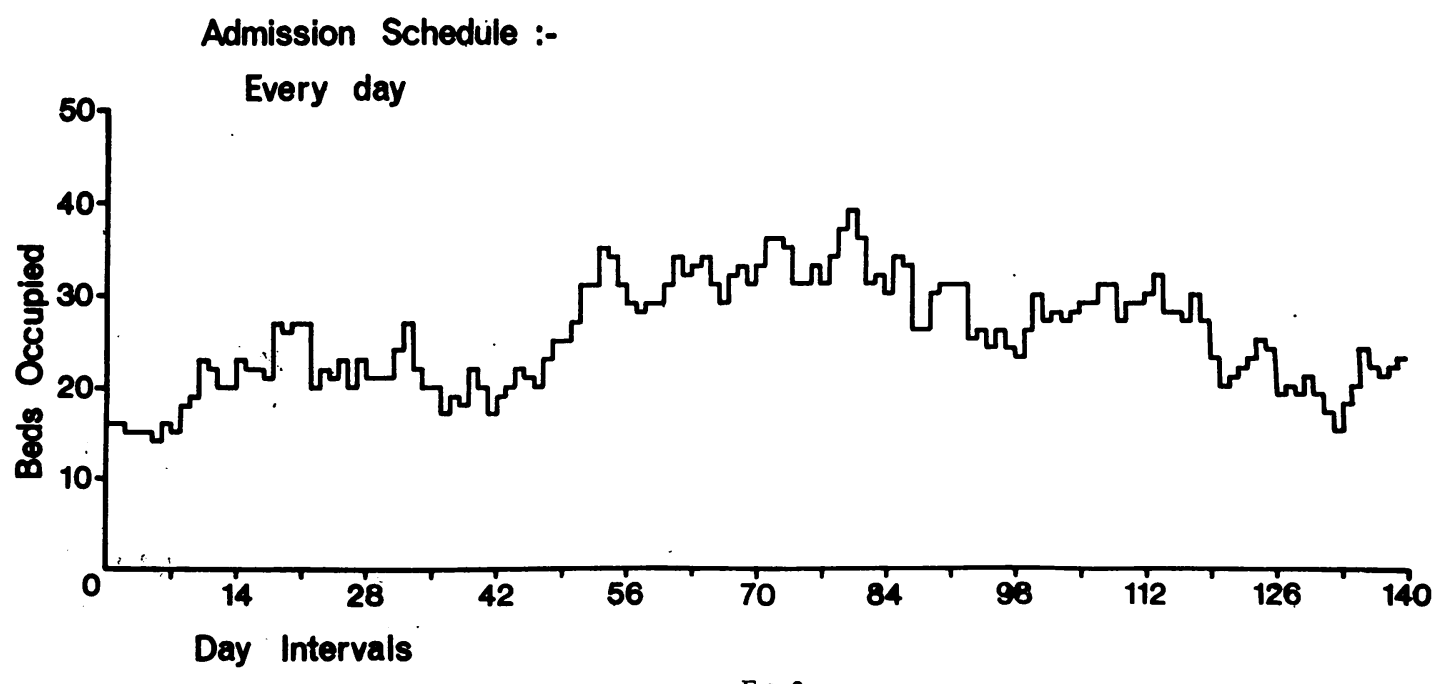

FIG. 2. 
numbers of patients admitted on each admission day are proportionately increased, giving rise to a concomitant increase in the day-to-day fluctuation. There are still about 10 beds constantly available for waiting-list patients, but the increased shortterm fluctuation reduces the facility with which the remaining beds may be used.

In large urban areas, it is common to find hospitals containing five or more separate units in the same clinical specialty, with rotational schedules involving all the units. Figure 7 shows the simulated bed occupancy sequence for one of five units, and Fig. 8 illustrates the sequence for one of six units. In botte instances, the admission of a large number of emergencies on one day of each week produces characteristically 'spiky' pattern of bed occupancy?. complicated by additional admissions every fifth of sixth week-end. It is not possible to guarantee thaf any beds will be available for patients other thaf emergencies, and the sudden changes in emergenco bed occupancy within short periods of time preclude the effective utilization of the remaining beds.

Returning to the admission schedules which mighê be adopted for combinations of two or three units

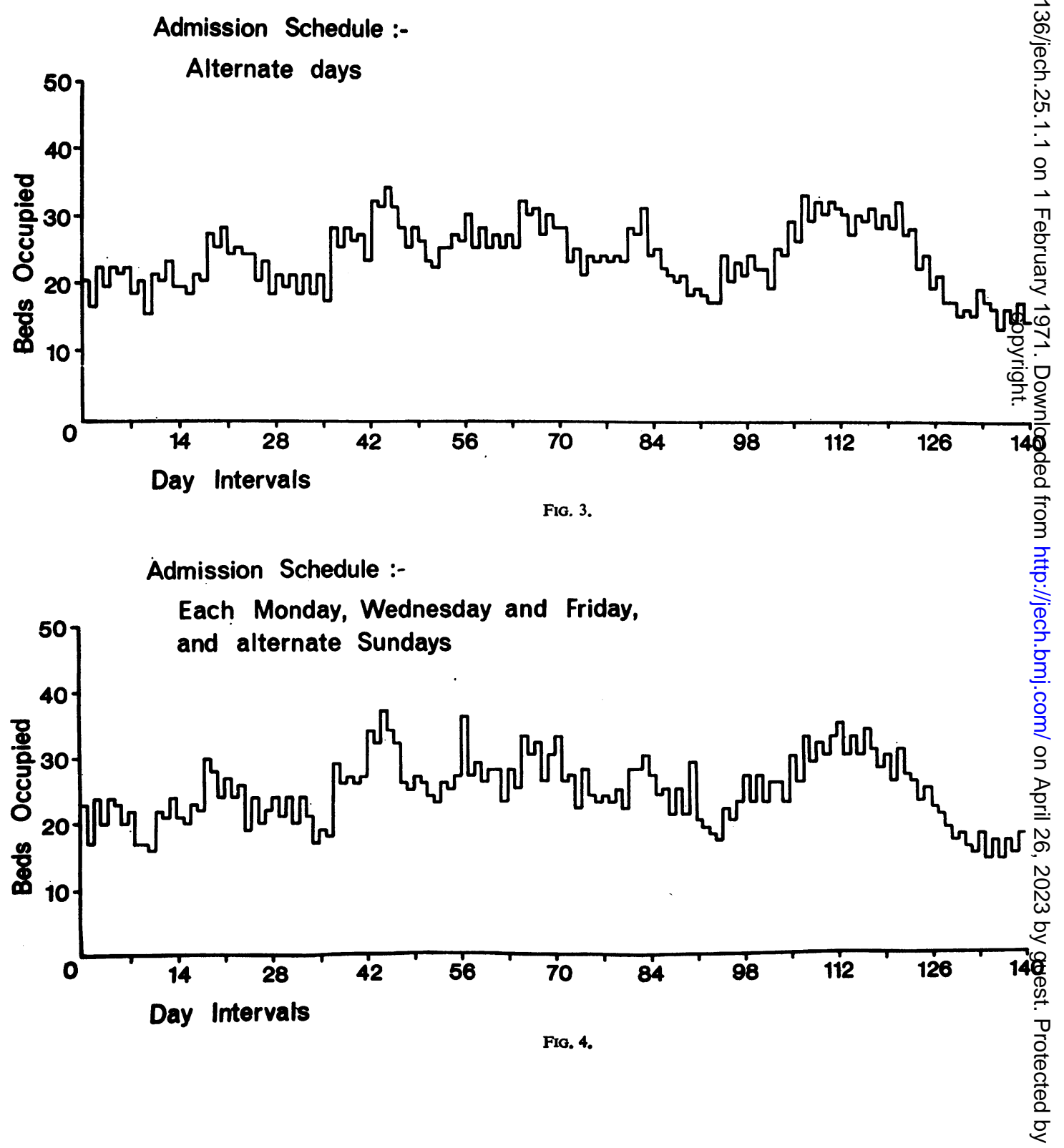


Figs 9 and 10 show the sequences occurring where individual units accept emergencies for periods of seven consecutive days. The numbers of admissions on each day are comparatively small, but the cumulative effect is substantial. In Fig. 10, there are two occasions when the numbers of beds required to accommodate emergency cases exceed the total number of beds available. While it is possible to predict that each peak in the emergency bed occupancy will be followed by a trough, it is uncertain precisely how many waiting-list patients could be accommodated. Further, the necessity to ensure the discharge of the great majority of waiting-list patients within a week of admission would present substantial administrative problems.

It must be emphasized that all of these simulated sequences of emergency bed occupancy were derived from the same mean daily emergency admission rate and the same distribution of duration of stay. The striking differences in the patterns of bed occupancy are entirely attributable to the characteristics of the various rotational admission schedules. The object of this part of the study was not to assess the precise effects of any of the schedules, but to illus-

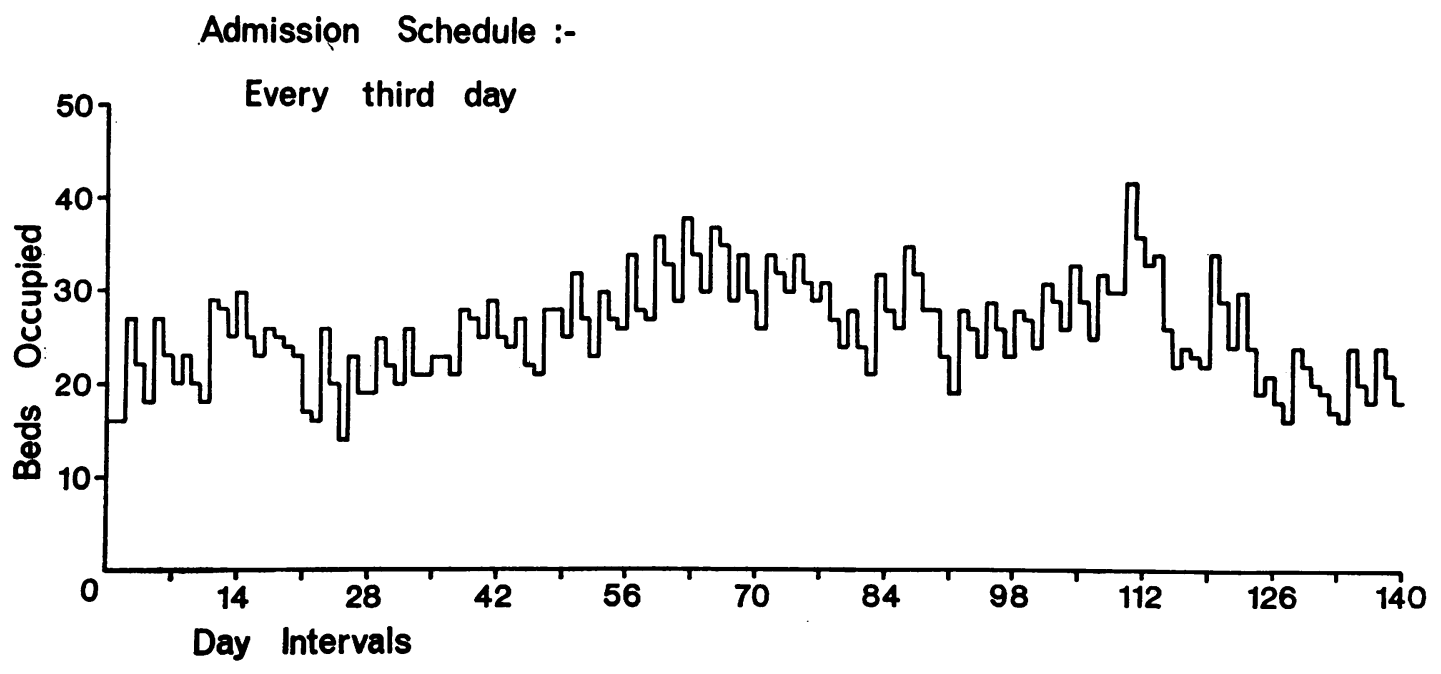

FiG. 5.

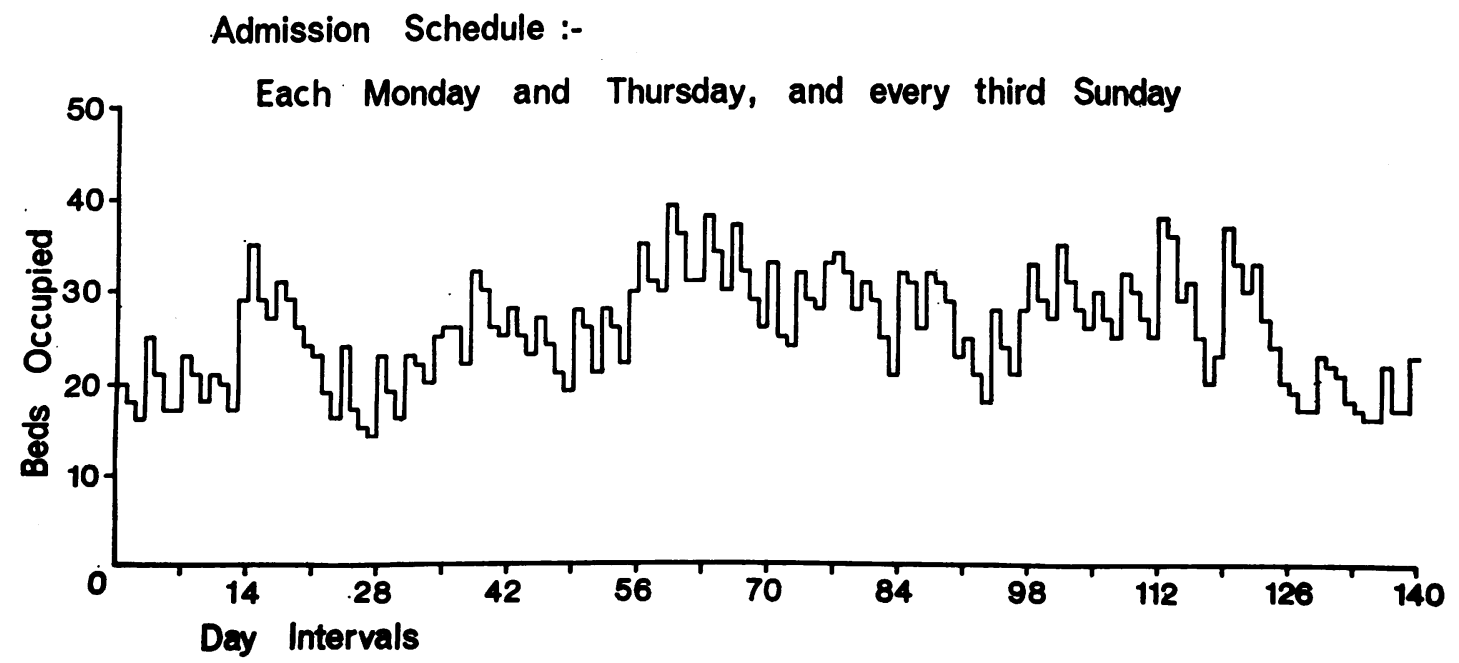

Fro. 6. 
trate the comparative effects of different schedules.

\section{Parameters}

The parameters which may be estimated statistically are (1) the mean bed occupancy; (2) the mean levels of bed occupancy associated with each of the days of an admission schedule; and (3) the probable upper limits of the numbers of admissions arising during periods of consecutive days of admission.

The first of these is self-explanatory, being the mean of the numbers of beds occupied from day to day, normally calculated as the product of the mean daily admission rate and the mean duration of stay With the observation that the numbers of beds occupied from day to day may also follow th Poisson distribution (Pike et al., 1963), the mean bed occupancy level seemed to assume a new sign ficance as a measure of the variance encountered ifi bed occupancy. However, the means and standare deviations relating to the bed occupancy sequences: presented in Figs 2 to 10 are given in Table I, and as may be seen, the standard deviations do net approximate to the square roots of the means in the sequences depicted by Figs 7 to 10. This appareed
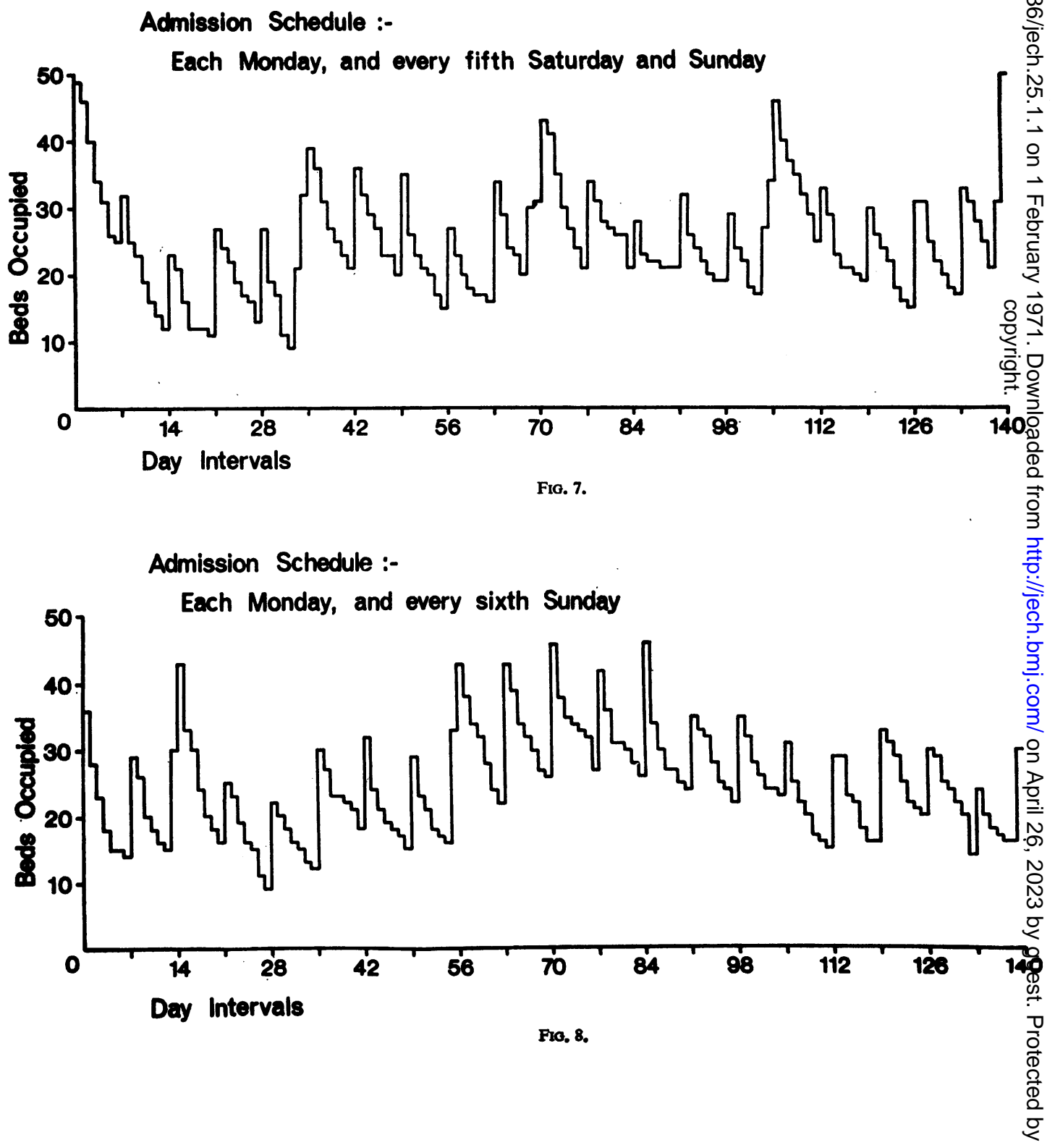
TABLE I

MEANS AND STANDARD DEVIATIONS OF BED OCCUPANCY RELATING TO SELECTED SIMULATED SEQUENCES

\begin{tabular}{|c|c|c|c|}
\hline Figure & Admission Schedule & $\begin{array}{l}\text { Mean Bed } \\
\text { Occupancy }\end{array}$ & Standard Deviation \\
\hline $\begin{array}{r}2 \\
3 \\
4 \\
5 \\
6 \\
7 \\
8 \\
9 \\
10\end{array}$ & $\begin{array}{l}\text { Every day } \\
\text { Every alternate day } \\
\text { Each Monday, Wednesday, and Friday, and alternate Sundays } \\
\text { Every third day } \\
\text { Each Monday and Thursday, and every third Sunday } \\
\text { Each Monday, and every fifth Saturday and Sunday } \\
\text { Each Monday, and every sixth Sunday } \\
\text { Each day during alternate weeks } \\
\text { Each day during every third week }\end{array}$ & $\begin{array}{l}25 \cdot 4 \\
24 \cdot 6 \\
24 \cdot 6 \\
25 \cdot 8 \\
25 \cdot 7 \\
25 \cdot 0 \\
25 \cdot 0 \\
24 \cdot 6 \\
25 \cdot 2\end{array}$ & $\begin{array}{r}5 \cdot 8 \\
4 \cdot 9 \\
5 \cdot 1 \\
5 \cdot 4 \\
5 \cdot 8 \\
7 \cdot 9 \\
7 \cdot 7 \\
7 \cdot 5 \\
12 \cdot 1\end{array}$ \\
\hline
\end{tabular}

Admission Schedule:-

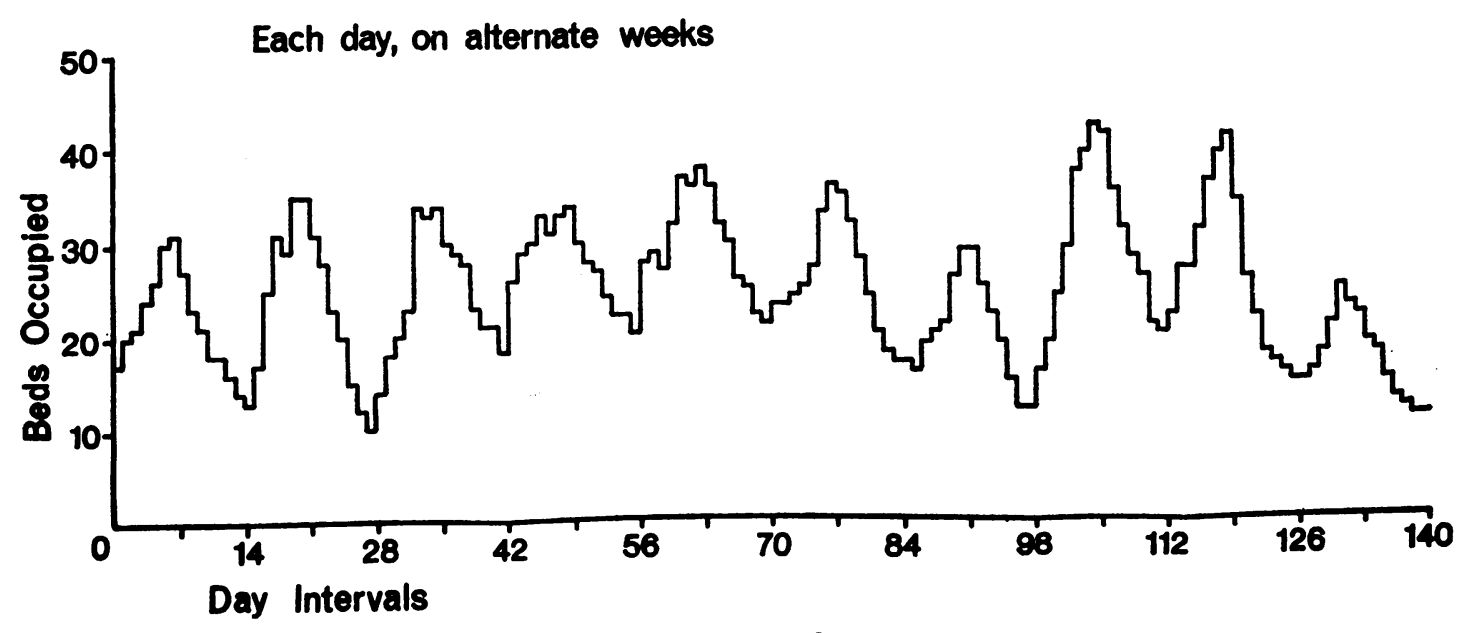

FrG. 9.

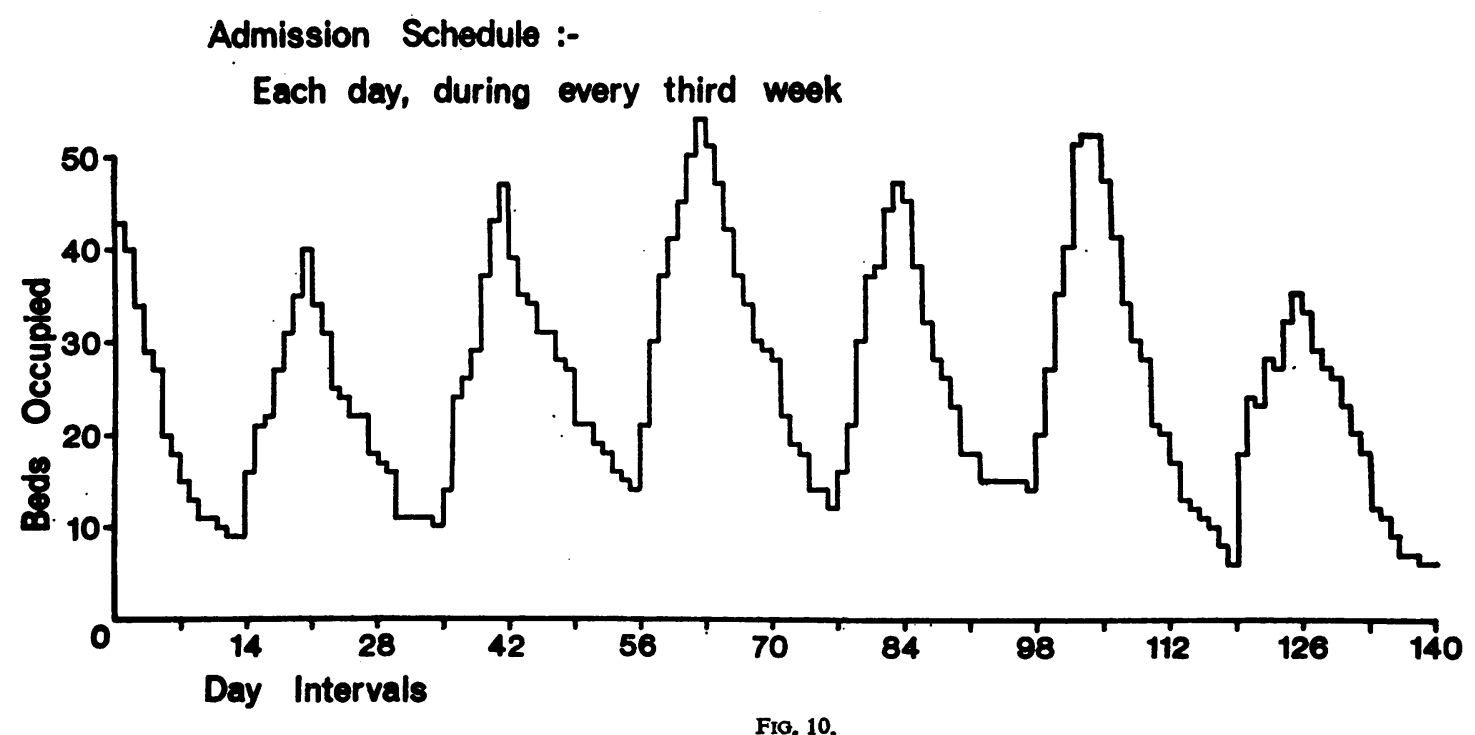

FIo. 10. 
contradiction of the findings of Pike et al., arises from the fact that they were dealing with the situation where emergencies are admitted every day, and the numbers of admissions from day to day follow the Poisson distribution. Where a rotational admission schedule is in operation, admissions follow the Poisson distribution if one considers only the days on which emergencies are admitted. Inasmuch as the admission schedule will determine a proportion of days on which no emergencies are admitted, largely irrespective of the mean daily admission rate, the overall day-to-day pattern of admissions cannot follow the Poisson distribution. Consequently, units participating in rotational admission systems do not fulfil the criterion of Pike et al., 'that the number of admissions on any particular day follows the Poisson distribution ... independent of the numbers of admissions on previous days and also independent of any other aspect of the system'.

In order to estimate the other parameters of bed use by emergencies, it is necessary to consider the 'effective' admission rate, described previously (Handyside and Morris, 1967) and used in this simulation process. It is derived by dividing the number of emergencies admitted by the number of days on which they were admitted. Thus, where emergencies are admitted every day, the 'effective' admission rate is identical with the estimated mean daily rate. In a hospital unit admitting 1,000 emergencies during a year,

$$
\text { effective admission rate }=\frac{1,000}{365}=2 \cdot 74 \text {. }
$$

However, where any other schedule for emergency admissions is used, the effective admission rate will be greater than the estimated mean daily rate. In a hospital unit admitting 1,000 emergencies during a year, accepting emergencies only on every third day,

$$
\text { effective admission rate }=\frac{1,000}{121 \cdot 7}=8 \cdot 22 ;
$$

and where the same number of emergencies is accepted during a year, but admitted on one weekday of each week, and at every fifth week-end,

$$
\text { effective admission rate }=\frac{1,000}{73}=13 \cdot 70 .
$$

The average number of beds occupied on each day during the cycle of an admission schedule may be estimated using the formula

$$
\Sigma p_{8} . m \text {, }
$$$$
\boldsymbol{s}
$$

where $p_{s}$ is the probability of a patient remaining $क$ in hospital, having been admitted $s$ days previously, 8 and $m$ is the effective admission rate for the schedule. 3 The distribution of $p_{s}$ is constructed from the ?․ distribution of duration of stay; and retrospective $\overrightarrow{\vec{F}}$ application of the pattern of admission days in the $\stackrel{\vec{F}}{+}$ schedule under consideration to this probability distribution permits summation of the appropriate $\frac{\bar{D}}{\overline{\mathrm{n}}}$ individual values of $p_{s}$. Table II shows the mean $\frac{\bar{D}}{\vec{D}}$ levels of bed occupancy for each day of each of the $\stackrel{\varnothing}{\triangle}$ schedules illustrated in Figs 2 to 10 . Because there $\%$ will be variation upon each of these mean values, $\vec{P}$ it is preferable to use simulation, where feasible, if a realistic picture of the fluctuations in emergency $\overrightarrow{\vec{\omega}}$ bed occupancy is desired.

Assuming that the day-to-day incidence of emer- $\stackrel{\mathbb{D}}{\circ}$ gencies requiring admission to hospital follows the $\vec{\sim}$ Poisson distribution, the probability of a number of $O$ emergencies requiring admission on a given day may be calculated from the Poisson function

$$
p_{x}=\frac{e^{-m} m^{x}}{x !}
$$

where $x$ is the number of admissions, $m$ is the effective admission rate, and $e$ is the exponential constant $(2 \cdot 718 \ldots)$. Given a number of independent $\vec{\varphi}$ Poisson distributions, $n$, with means $m_{1}, m_{2}, \ldots m$ m respectively, the joint distribution of these variable will be Poisson, with mean

$$
M=m_{1}+m_{2} \ldots+m_{n}
$$

(Cramér, 1955). Thus, in those admission schedules where two or more admission days occur consecutively, the admission rate for the group of con- $\stackrel{\Omega}{\overrightarrow{7}}$ secutive days may be regarded as the product of the effective admission rate and the number of consecutive days.

In order to assess the number of admissions, $\varnothing$, which will occur with a particular probability during the largest number of consecutive admission days? characteristic of an admission schedule, the upper 3 tail of the Poisson distribution, corresponding to this probability, is calculated. The probability of $\varnothing \frac{\circ}{3}$ emergencies arriving once in every hundred admission cycles is 0.01 . Thus,

$$
1-\sum_{x=0}^{\varnothing} \frac{e^{-M} M^{x}}{x !}=0.01
$$

where $M$ is the product of the effective admission $N$ rate and the number of consecutive days in the ad- N mission period. Hence, values of $\varnothing$ are readily obtained from published tables, using

$$
\sum_{x=0}^{\varnothing} \frac{e^{-M} M^{x}}{x !}=0.99
$$


The probability of $ø$ occurring once every year is $\frac{K}{365}$, where $K$ is the length, in days, of the admission cycle, the minimum number of days required to complete the admission schedule. Thus, similarly, values of $\varnothing$ may be obtained, using

$$
\sum_{x=0}^{\varnothing} \frac{e^{-M} M^{x}}{x !}=1-\frac{K}{365}
$$

Table III shows the probable upper limits of the numbers of admissions which could occur during the longest admission periods characteristic of the admission schedules illustrated in Figs 2 to 10, assuming that each 50-bed unit would admit 1,000 emergencies each year. While the effects on bed occupancy of the large numbers of admissions which may be expected in some schedules will be offset by simultaneous discharges, every admission generates work for the hospital staff, so that excessive numbers of admissions over short periods of time are undesirable.

TABLE II

ESTIMATED AVERAGE LEVELS OF EMERGENCY BED OCCUPANCY FOR EACH DAY DURING ILLUSTRATED ADMISSION SCHEDULES

\begin{tabular}{|c|c|c|c|c|c|c|c|c|}
\hline \multirow{2}{*}{ Admission Schedule } & \multirow{2}{*}{$\begin{array}{l}\text { Duration } \\
\text { of } \\
\text { Cycle } \\
\text { (days) }\end{array}$} & \multirow{2}{*}{ Day } & \multicolumn{6}{|c|}{ Week } \\
\hline & & & 1 & 2 & 3 & 4 & 5 & 6 \\
\hline Every day & 1 & 1 & $25 \cdot 5 *$ & & & & & \\
\hline Every alternate day & 2 & $\begin{array}{l}1 \\
2\end{array}$ & $\begin{array}{l}26 \cdot 9 \cdot \\
24 \cdot 0\end{array}$ & & & & & \\
\hline Each Monday, Wednesday, and Friday, and alternate Sundays & 14 & $\begin{array}{l}1 \\
2 \\
3 \\
4 \\
5 \\
6 \\
7\end{array}$ & $\begin{array}{l}28.8^{\circ} \\
25 \cdot 6 \\
28.4 \\
25 \cdot 3 \\
28 \cdot 2^{*} \\
25 \cdot 1 \\
22.5\end{array}$ & $\begin{array}{l}25 \cdot 6^{*} \\
22 \cdot 8 \\
25 \cdot 8^{\circ} \\
22.9 \\
26 \cdot 0^{\circ} \\
23 \cdot 1 \\
26 \cdot 2^{*}\end{array}$ & & & & \\
\hline Every third day & 3 & $\begin{array}{l}\mathbf{1} \\
\mathbf{2} \\
\mathbf{3}\end{array}$ & $\begin{array}{l}28 \cdot 5 \\
25 \cdot 3 \\
22 \cdot 6\end{array}$ & & & & & \\
\hline Each Monday and Thursday, and every third Sunday & 21 & $\begin{array}{l}1 \\
2 \\
3 \\
4 \\
5 \\
6 \\
7\end{array}$ & $\begin{array}{l}32 \cdot 6^{\circ} \\
28 \cdot 8 \\
25 \cdot 9 \\
31 \cdot 4^{*} \\
27 \cdot 8 \\
25 \cdot 1 \\
22 \cdot 5\end{array}$ & $\begin{array}{l}28 \cdot 2 \\
24 \cdot 9 \\
22 \cdot 3 \\
28 \cdot 1 * \\
24 \cdot 9 \\
22 \cdot 4 \\
20 \cdot 2\end{array}$ & $\begin{array}{l}26 \cdot 2 \\
23 \cdot 2 \\
20.9 \\
26 \cdot 8 \\
23.7 \\
21.4 \\
27.5\end{array}$ & & & \\
\hline Each Monday, and every fifth Saturday and Sunday & 35 & $\begin{array}{l}1 \\
2 \\
3 \\
4 \\
5 \\
6 \\
7\end{array}$ & $\begin{array}{c}48 \cdot 2 \cdot \\
42 \cdot 3 \\
37 \cdot 9 \\
34 \cdot 2 \\
31 \cdot 1 \\
28 \cdot 1 \\
24 \cdot 9\end{array}$ & $\begin{array}{l}35 \cdot 4 * \\
30 \cdot 7 \\
27 \cdot 2 \\
24 \cdot 6 \\
22 \cdot 2 \\
20 \cdot 2 \\
18 \cdot 2\end{array}$ & $\begin{array}{l}29 \cdot 8 * \\
26.0 \\
23 \cdot 1 \\
20.9 \\
19 \cdot 0 \\
17.5 \\
15.9\end{array}$ & $\begin{array}{l}27 \cdot 8 * \\
24 \cdot 2 \\
21 \cdot 5 \\
19 \cdot 3 \\
17 \cdot 5 \\
15.9 \\
14 \cdot 5\end{array}$ & $\begin{array}{l}26.6 * \\
23.0 \\
20.5 \\
18.4 \\
16.7 \\
28.9 \\
39 \cdot 3\end{array}$ & \\
\hline Each Monday, and every sixth Sunday & 42 & $\begin{array}{l}1 \\
2 \\
3 \\
4 \\
5 \\
6 \\
7\end{array}$ & $\begin{array}{l}44 \cdot 7 \cdot \\
38 \cdot 9 \\
34 \cdot 7 \\
31 \cdot 3 \\
28 \cdot 3 \\
25 \cdot 9 \\
23 \cdot 2\end{array}$ & $\begin{array}{l}36 \cdot 7{ }^{\circ} \\
31 \cdot 8 \\
28 \cdot 1 \\
25 \cdot 3 \\
22.9 \\
20.9 \\
19 \cdot 0\end{array}$ & $\begin{array}{l}33 \cdot 1 \\
28.8 \\
25.6 \\
23.0 \\
20.9 \\
19.2 \\
17.5\end{array}$ & $\begin{array}{l}31 \cdot 9 \\
27 \cdot 6 \\
24 \cdot 6 \\
22 \cdot 1 \\
20 \cdot 0 \\
18 \cdot 3 \\
16 \cdot 6\end{array}$ & $\begin{array}{l}31 \cdot 2 \\
27.0 \\
23.9 \\
21 \cdot 5 \\
19 \cdot 5 \\
17.8 \\
16.2\end{array}$ & $\begin{array}{l}30.7 \\
26.6 \\
23.6 \\
21 \cdot 3 \\
19.3 \\
17 \cdot 6 \\
32.4\end{array}$ \\
\hline Each day during alternate weeks & 14 & $\begin{array}{l}1 \\
2 \\
3 \\
4 \\
5 \\
6 \\
7\end{array}$ & $\begin{array}{l}19.7 \% \\
22.99^{\circ} \\
25 \cdot 8^{\circ} \\
28.4^{\circ} \\
30.8^{\circ} \\
33.0^{\circ} \\
35.0^{\circ}\end{array}$ & $\begin{array}{l}31 \cdot 3 \\
28 \cdot 0 \\
25 \cdot 2 \\
22 \cdot 5 \\
20 \cdot 2 \\
18 \cdot 0 \\
16 \cdot 0\end{array}$ & & & & \\
\hline $\begin{array}{l}\text { Each day during every third week } \\
\text {. . }\end{array}$ & 21 & $\begin{array}{l}1 \\
2 \\
3 \\
4 \\
5 \\
6 \\
7\end{array}$ & 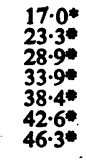 & $\begin{array}{l}41 \cdot 3 \\
36 \cdot 9 \\
33 \cdot 1 \\
29 \cdot 4 \\
26 \cdot 2 \\
23 \cdot 2 \\
20 \cdot 5\end{array}$ & $\begin{array}{r}18 \cdot 1 \\
16 \cdot 2 \\
14 \cdot 5 \\
13 \cdot 1 \\
11 \cdot 8 \\
10 \cdot 6 \\
9 \cdot 6\end{array}$ & & & \\
\hline
\end{tabular}


TABLE III

UPPER LIMITS OF NUMBERS OF ADMISSIONS LIKELY TO OCCUR DURING LONGEST ADMISSION PERIODS CHARACTERISTIC OF SELECTED EMERGENCY ADMISSION SCHEDULES*

\begin{tabular}{|c|c|c|c|}
\hline \multirow[b]{2}{*}{ Admission Schedule } & \multirow{2}{*}{$\begin{array}{c}\text { Longest } \\
\text { Admission } \\
\text { Period } \\
\text { (days) }\end{array}$} & \multicolumn{2}{|c|}{ Highest No. of Admissions } \\
\hline & & $\begin{array}{l}\text { Once Every } \\
100 \text { Cycles }\end{array}$ & $\begin{array}{c}\text { Once Every } \\
\text { Year }\end{array}$ \\
\hline $\begin{array}{l}\text { Every day } \\
\text { Every alternate day } \\
\text { Each Monday, Wednesday, and Friday, and alternate Sundays } \\
\text { Every third day } \\
\text { Each Monday and Thursday, and every third Sunday } \\
\text { Each Monday, and every fifth Saturday and Sunday } \\
\text { Each Monday, and every sixth Sunday } \\
\text { Each day during alternate weeks } \\
\text { Each day during every third week }\end{array}$ & $\begin{array}{l}1 \\
1 \\
2 \\
1 \\
2 \\
3 \\
2 \\
7 \\
7\end{array}$ & $\begin{array}{r}7 \\
12 \\
19 \\
16 \\
27 \\
57 \\
47 \\
53 \\
76\end{array}$ & $\begin{array}{r}8 \\
12 \\
17 \\
16 \\
23 \\
50 \\
40 \\
50 \\
70\end{array}$ \\
\hline
\end{tabular}

-For individual 50-bed units each admitting 1,000 emergencies during a year.

\section{Discussion}

The management problems associated with the emergency admission of patients to hospital are:

(a) the requirement of ensuring that beds are immediately available for all patients in need of emergency admission;

(b) the desirability of optimizing the utilization of beds for the benefit of both emergency and waiting list patients; and

(c) the necessity to maintain an adequate, but not excessive, work-load for medical, nursing, and ancillary staffs.

The greater the fluctuations which occur in the emergency bed occupancy, the more apparent these problems become. Since it is possible neither totally to eliminate the fluctuations nor precisely to predict their extent, these problems cannot be avoided. As has been shown, however, the extent of the fluctuations is substantially affected by the admission schedule which is in operation. It is possible to identify certain features of emergency admission schedules, whose modification may alleviate some of the difficulties encountered.

Where the emergency admission schedules of a small number of hospital units are associated in a rotational admission system, the effective admission rate for each unit tends to be reduced, and sudden extreme changes in emergency bed occupancy become rare. Conversely, where the number of units involved is large, the effective admission rate is proportionately increased; and, depending upon the magnitude of the admission rate, all the problems associated with emergency admissions may be considerably aggravated. Whenever it can be anticipated that a large number of patients will require immediate admission to an individual hospital unit over a period of a few days, administrative choice rests between the risk of overcrowding and the possibility of poor levels of utilization of beds. In addition, the work-load associated with emergency admission procedures and immediate treatment may become excessive. If, in a large urban area, sever? individual hospital units within the same clinical specialty accept emergencies on a rotational basis, it may be worth while to 'pair' them so that no single unit accepts the entire emergency load on any one day.

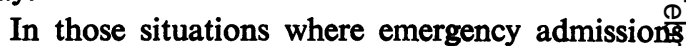
are shared between a small number of individual units, or between larger numbers of units working in pairs, it is still possible for particular admissio schedules to present difficulties. If, as in Fig. three units are involved, each accepting engeg gencies for a week at a time, the effective admis\$口 rate and the day-to-day fluctuations remain with tolerable limits; but the cumulative effect of sevel consecutive days of admission may be very deman ing, both in terms of the numbers of beds which have to be made available and in the work-load imposed on the staff. In general, it is probably in advisable for any hospital unit participating in $\frac{\text { F }}{8}$ rotational admission system to accept emergencies for more than three consecutive days. The cums lative effect of consecutive days of admission is en hanced by high mean daily admission rates, so tha prolonged admission periods should always avoided in units characterized by high levels of emergency turnover.

In many existing British hospitals, attempts to select rotational systems of admission schedules which will conserve resources of personnel and equipment are perhaps of greater significance in the surgical specialties, where operating theatres may be associated, physically or notionally, with wari units. In a large hospital, it may seem more econo 0 mical to have a single ward unit and its theatre of emergency standby each day, than to have two more wards and theatres dealing with emergencio simultaneously. This problem may be overcome in newer hospitals, where operating theatre facilities 
are centralized, so that 'ownership' of particular theatres by particular surgical units can be more effectively resisted and broader consideration given to the more effective use of all physical resources.

The selection of a related system of admission schedules for use by a number of hospital units should not be merely a matter of apparent administrative convenience. Depending on the numbers of patients requiring admission, and the number of hospital units involved, the adoption of particular emergency admission schedules may have profound effects on the way in which inpatient resources are used, on the work-load which has to be undertaken by the staff immediately concerned, and on the despatch of treatment for the patients.

\section{SUMmaRY}

This paper illustrates the results obtained by computer simulation of selected emergency admission schedules which might be used where a number of individual hospital units accept emergencies on a rotational basis. Methods for the statistical estimation of certain parameters of emergency bed use are presented. The possibility of avoiding some of the difficulties associated with the admission of emergencies, by consideration of the general effects of admission schedules, is discussed.

For technical assistance in various ways we are grateful to Miss D. Linklater, Mr. R. A. MacNay, Mr. J. D. L. Morris, Miss J. Pickering, and Mr. K. Trout.

This work was carried out in the Medical Care Research Unit of the Department of Preventive Medicine and Pub- lic Health at Sheffield University, and was supported financially by the Department of Health and Sheffield Regional Hospital Board.

Requests for reprints should be addressed to Dr. D. Morris, Newcastle Regional Hospital Board, Benfield Road, Walker Gate, Newcastle upon Tyne NE6 4PY.

\section{REFERENCES}

BalintFy, J. L. (1960). A stochastic model for the analysis and prediction of admissions and discharges in hospitals. Management Sciences, Models and Techniques: Proceedings of the Sixth International Meeting of the Institute of Management Sciences, Vol. 2, p. 288. Pergamon, Oxford.

Cramer, H. (1955). The Elements of Probability Theory, p. 104. John Wiley, New York.

Gibson, J. R., Hughes, T. L., and Broughton, A. V. L. (1958). Ease of admission to hospital of medical and surgical emergencies. Med. Offr, 99, 117.

HANDYSIDE, A. J., and MorRIs, D. (1967). Simulation of emergency bed occupancy. Hith Serv. Res., 2, 287.

Morris, D., Hall, G. A., and HaNdyside, A. J. (1969). Admissions from surgical waiting lists. Brit. J. prev. soc. Med., 23, 233.

Newell, D. J. (1954). Provision of emergency beds in hospitals. Brit. J. prev. soc. Med., 8, 77.

Pike, M. C., Proctor, D. M., and Wyllie, J. M. (1963). Analysis of admissions to a casualty ward. Brit. J. prev. soc. Med., 17, 172.

WARren, M. D., COOPER, J., and WARren, J. L. (1967). Problems of emergency admissions to London hospitals. Brit. J. prev. soc. Med., 21, 141.

YounG, J. P. (1965). Stabilization of inpatient bed occupancy through control of admissions. Hospitals, 39, no. 19 (October 1), 41. 